\title{
Anatomical and surgical study of volume determination of the anterolateral epidural space nerve root L5/S1 under the aspect of epidural perineural injection in minimal invasive treatment of lumbar nerve root compression
}

\author{
Wolfram Teske $\cdot$ Sonja Zirke $\cdot$ Jan Nottenkämper • \\ Thomas Lichtinger - Theodoros Theodoridis • \\ Jürgen Krämer · Klaus Schmidt
}

Received: 18 February 2010/Revised: 3 May 2010/ Accepted: 11 June 2010/Published online: 30 June 2010

(C) The Author(s) 2010. This article is published with open access at Springerlink.com

\begin{abstract}
Herniated intervertebral disc causes in a great number of cases of lumbar nerve root compression, especially in the segment L5/S1. Other reasons responsible for stress to the lumbar spinal root are the spinal canal stenosis and the postdiscotomy syndrome. For patients without neurological deficiencies, the conservative treatment includes different epidural injection techniques. Steroids are often applied. A specific injection technique needing only a small drug amount is the epidural perineural approach using a special two-needle technique. The anatomical spaces of the nerve roots have received little attention in therapy. We have determined the anterolateral epidural space nerve volume of the nerve root L5/S1, and compared the data collected in an anatomical study with operative measurements during discectomy. The volume determination in the human cadavers was performed with liquid silicone filling the anterolateral space after dissection. The in vivo measurements were performed during surgery at the site of the anterolateral space after discectomy. The anatomical studies showed us a mean value volume of $1.1 \mathrm{ml}$. The surgical volume determinations result in a mean volume of $0.9 \mathrm{ml}$. A better understanding of the anterolateral epidural space may allow a reduction of the injection
\end{abstract}

W. Teske $(\bowtie) \cdot J$. Nottenkämper · T. Lichtinger Orthopädische Universitätsklinik am St. Josef Hospital, Ruhr Universität Bochum, Gudrunstrasse 56, 44791 Bochum, Germany

e-mail: wolfram.teske@rub.de

S. Zirke $\cdot$ T. Theodoridis · J. Krämer

Institut für Wirbelsäulenforschung an der Ruhr Universität Bochum, Viktoriastr. 66-70, 44787 Bochum, Germany

K. Schmidt

Kath. Krankenhaus Dortmund-West, Zollernstrasse 40, 44379 Dortmund, Germany volume in the conservative nerve root compression treatment, especially using the epidural perineural technique, avoiding the risk of side effects of high doses of steroids.

Keywords Lumbar nerve root compression .

Anatomical volume determination .

Epidural-perineural injection technique

\section{Introduction}

Epidural injections play a crucial role in the conservative treatment of the lumbar spine nerve compression syndrome. The primary indication is the treatment of herniated vertebral disc, the lumbar spinal canal stenosis and the post discectomy syndrome. Different application techniques are known to reach the requested nerve root. In most cases the roots L5 and S1 are affected.

In general, the injected therapeutic substance is a local anaesthetic often in combination with a corticosteroid for antiphlogistic purpose. A number of different injection techniques are described in literature. Each special technique requires a different drug volume for best results under the aspect of analgesia and anti-inflammatory effect. The common epidural injection needs a dose of $40-80 \mathrm{mg}$ triamcinolone in a volume of $10-20 \mathrm{ml}$ using the loss of resistance technique $[3,6,7,10]$. The similar epidural sacral injection in the hiatus sacralis needs equal amounts glucosteroids in similar volumes [2, 5, 10]. The epidural-peridural interlaminar approach allows an injection in the anterolateral space containing the roots L5 and S1 [4]. This method requires rather smaller injection volume and a much lower dose of steroids in comparison to the other methods because the application takes place in direct contact to the affected nerve root. 
The anterolateral epidural space between the L5 root and the passage of the S1 root as the target of the injection therapy has an estimated volume of $2 \mathrm{ml}[4,9]$. The amount of triamcinolone required was first given with $10 \mathrm{mg}$ triamcinolone [4]. The randomized controlled study from Becker et al. [1] reduced the dose from 10 to $5 \mathrm{mg}$ triamcinolone/injection. To determine the needed volume for an epidural-perineural injection, it makes sense to examine the capacity of the antero-lateral epidural space L5/S1.

\section{Materials and methods}

Twelve human cadaver spines were dissected cranial at level Th12 and caudal at the level of the cranial third of the sacral spine. Both the segments L5/S1 were marked with a needle. The correct needle position was controlled radiologically in three planes. A radiograph of the complete dissected spine was performed to proof regular anatomical spine structure. Cadavers with obvious diseases, scoliosis, M. Bechterew and fracture deformity were excluded from the study. The topographic anatomy of the nerve roots L5/S1 is shown in Fig. 1 in depth. The preparation of the L5/S1 area was done by dorsal approach. The soft tissue was removed until the Ligamentum flavum was reached. The epidural fat pad was dissected meticulously. The vertebral arches were preserved. As the result of the preparation a cavity was formed. The cavity borders are cranial the nerve root L5, caudal the sacral bone, lateral the complex of the facet and medial the dural sheath and the S1 root.

The volume determination was performed with liquid silicone. The silicone is regularly in use to perform dental impressions by dental surgeons. This impression material is fluid. To start the time-dependent curing procedure, the components will be mixed in a cylinder and perform a soft crosslinked material layer. The application is done by direct application of the material from the cylinder (Fig. 2). The advantages of the method are the dispersion of the viscous material only under pressure and visual control of the examiner. The hardening process is fast. After setting, the dental silicone is easy to remove. It is not adherent to anatomical structures, which allows the complete removal of the silicone filling in one piece. A forceps for removal of herniated disc was used for this purpose (Fig. 3).

The volume measurement was performed using the principle of water displacement. The graduated measuring glass had a volume of $5 \mathrm{ml}$ and was scaled in $0.1 \mathrm{ml}$ intervals. Each epidural space of 11 spine cadavers underwent the complete procedure four times. One cadaver was measured only at the right side. The left side of this specimen was violated during the dissection process, and was then excluded from further investigation.

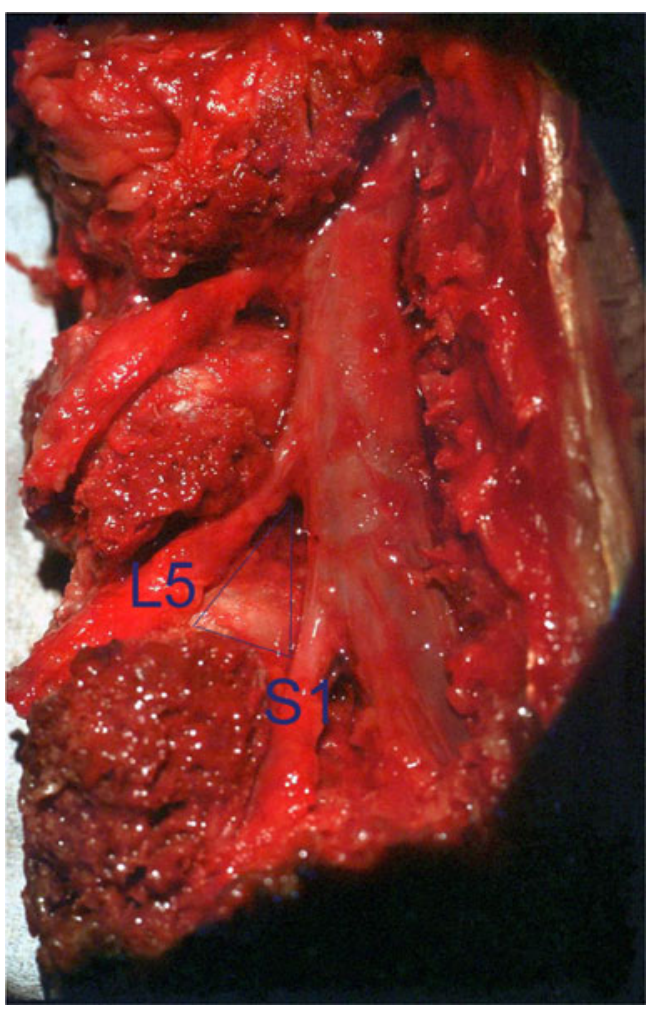

Fig. 1 Lumbar spine specimen in a left laterodorsal sight after removal of the laminae and the facet joints. The roots L5/S1 and the upper part of the sacral bone form a triangle with the disc in the lower part. Between the pedicles L5 and the sacral bone the nerve root L5 exits the vertebral foramen L5/S1. The S1 root traverses the disc L5/S1 in its dorsolateral part. The nerve root L5 is situated at the disc level only in the lateral part of the vertebral foramen. The triangle nerve root L5, nerve root S1 and upper part of the sacral bone forms the anterolateral space L5/S1. This space is prone to the radicular pain symptoms of the L5 and S1 roots. The root L5 is compromised in top part of the triangle by disc protrusions and herniations at the level of the disc L5/S1 and below. Even slipped hernias from above could irritate the root L5. The disc traversing root S1 could be affected the complete distance. The injection of a local anaesthetic or an antiphlogistic in this space achieves the roots L5 and S1

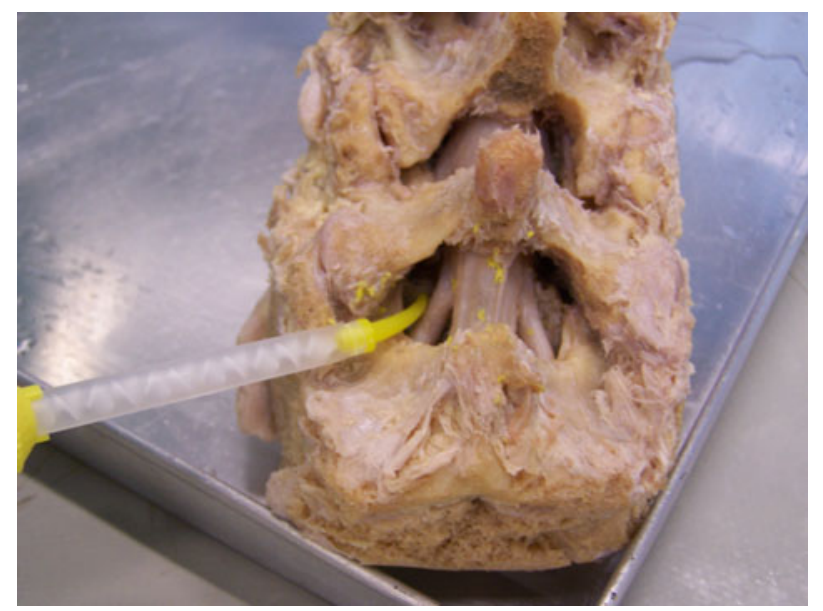

Fig. 2 Filling of the anterolateral epidural space with dental silicone 


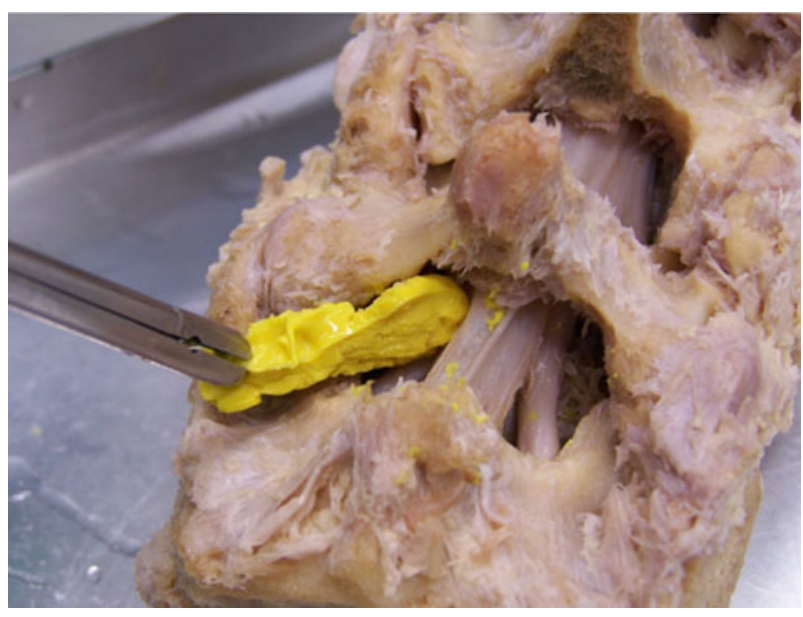

Fig. 3 Removal of silicone for measurement using forceps

All registrations were then performed in the described method independently by a second examiner.

\section{Results}

Comparison of mean volume values, standard deviations and significance of the right and the left side

The right sides of all cadavers could be examined. 12 single-point registrations were collected in each run of measurement. The mean values, the standard deviation and the significance for the right side were determined (Table 1). The mean volume varies between $1.03 \mathrm{ml}$ (volume right side run 1) and $1.13 \mathrm{ml}$ (volume right side run 4) with standard deviations between 0.25 (run 1) and 0.17 (run 4). The left sides of 11 specimens were examined identically (Table 2 ). The mean volume varies between $1.02 \mathrm{ml}$ (volume left side run 1) and $1.13 \mathrm{ml}$ (volume left side run 4). The maximum standard deviation for the left side was 0.25 (run 1), and the minimum standard deviation was 0.17 (run 4). For all measurement the significance niveau was $p>0.05$. Hence, no significant difference was detected between the different series of measurement regarding the volume values of the right and left side in the different cadavers.

Comparison of measurement results between the two examiners

For this step, all 12 spine cadavers could be used. The results of the collected mean volume values from both investigators showed a value of $1.13 \mathrm{ml}$. The standard deviation and the significance level for all single measurements result in a $p$ value of $>0.05$ and showed no significant difference between the measurement results.
Table 1 Comparison of the mean values, the standard deviation and the significance niveau of the right side measurement

\begin{tabular}{|c|c|c|c|c|}
\hline & $\begin{array}{l}\text { Mean } \\
\text { value (ml) }\end{array}$ & $N$ & $\begin{array}{l}\text { Standard } \\
\text { deviation }\end{array}$ & $\begin{array}{l}\text { Significance } \\
\text { niveau }\end{array}$ \\
\hline \multicolumn{5}{|c|}{ Measurements 1 and 2} \\
\hline Volume right 1 & 1.03 & 12 & 0.25 & NS \\
\hline Volume right 2 & 1.12 & 12 & 0.26 & NS \\
\hline \multicolumn{5}{|c|}{ Measurements 2 and 3} \\
\hline Volume right 2 & 1.12 & 12 & 0.26 & NS \\
\hline Volume right 3 & 1.1 & 12 & 0.18 & NS \\
\hline \multicolumn{5}{|c|}{ Measurements 3 and 4} \\
\hline Volume right 3 & 1.1 & 12 & 0.18 & NS \\
\hline Volume right 4 & 1.13 & 12 & 0.17 & NS \\
\hline
\end{tabular}

Table 2 Comparison of the mean values, the standard deviation and the significance niveau of the left side measurement

\begin{tabular}{|c|c|c|c|c|}
\hline & $\begin{array}{l}\text { Mean } \\
\text { value (ml) }\end{array}$ & $N$ & $\begin{array}{l}\text { Standard } \\
\text { deviation }\end{array}$ & $\begin{array}{l}\text { Significance } \\
\text { niveau }\end{array}$ \\
\hline \multicolumn{5}{|c|}{ Measurements 1 and 2} \\
\hline Volume left 1 & 1.02 & 11 & 0.25 & NS \\
\hline Volume left 2 & 1.04 & 11 & 0.23 & NS \\
\hline \multicolumn{5}{|c|}{ Measurements 2 and 3} \\
\hline Volume left 2 & 1.04 & 11 & 0.23 & NS \\
\hline Volume left 3 & 1.07 & 11 & 0.15 & NS \\
\hline \multicolumn{5}{|c|}{ Measurements 3 and 4} \\
\hline Volume left 3 & 1.07 & 11 & 0.15 & NS \\
\hline Volume left 4 & 1.13 & 11 & 0.17 & NS \\
\hline
\end{tabular}

\section{Living measurement during operation}

The aim of this part of the study was to figure out a possible difference between the determination of the volume in cadavers and living humans. In addition to the collected experimental data using the dental filling procedure in the anatomical laboratory, operative measurements were performed in the theatre. All patients gave informed consent for the measurement. All operations were performed by one of two experienced senior spine surgeons.

The measurements were performed on patients, who underwent spine surgery for removal of herniated disc in the segment L5/S1. After completion of the operation, the now available anterolateral epidural space L5/S1 was filled with $0.9 \%$ saline with a bulb headed cannula under visual control. A remarkable bleeding during surgery was a criterion for exclusion from the volume determination. 21 measurements could be performed. The saline volume was determined. The results alternate between 0.6 and $1.5 \mathrm{ml}$ with a mean value of $0.9 \mathrm{ml}$. The saline fluid level was steady in the filled epidural space. Our group interpret this 
interesting finding as an attribute for the anatomical closeness of the anterolateral epidural space.

\section{Discussion}

Many physicians use the CT scan or an image intensified $\mathrm{C}$-arm X-ray unit to control the injection technique at the lumbar spine. A great number of patients suffer pain from recurrent lumbar spinal root compression syndromes for a long time. As a result, they receive a high number of radiologically based injections with a high exposure to radiation. The high doses of corticosteroids needed in common injection techniques are a preventable drug risk for the patient. The epidural dorsal technique and the epidural sacral technique in the loss-off-resistance technique need a volume from 10 to $20 \mathrm{ml}$ saline with a corticosteroid suspension of $40-80 \mathrm{mg}$ to reach the affected nerve root with a therapeutic potent dose $[3,6,7,10]$. In our opinion, this treatment concept follows the rules of a "watering can principle". The epineural peridural injection in the antero-lateral epidural space reaches the affected nerve root directly [4]. This special two-needle technique requires a much smaller injection volume. In consequence, the corticosteroid dose is much smaller to achieve the therapeutic effect. A 2-ml volume and a required dose of $10 \mathrm{mg}$ triamcinolone were estimated first [4]. The research of our group could reduce the drug dose to a value of $5 \mathrm{mg}$ triamcinolone [1]. Local anaesthetics showed good results using this technique, too [8].

The data of the anatomical experiments presented here using dental silicone showed volume between 0.6 and $1.4 \mathrm{ml}$ with a mean value of $1.1 \mathrm{ml}$ for the antero-lateral epidural space. These experimental collected data were affirmed by observations during surgery in the segment L5/ $\mathrm{S} 1$. The volume determinations are significantly smaller than until today estimated $2 \mathrm{ml}$ volume. The data of the surgical volume determination are consistent and support the results of the anatomical study strongly.

In the discussion of avoidable iatrogenic high doses of corticosteroids in the human body, we focus on the publication of the $\mathrm{Ng}$ group [6]. This group found no difference between a study group with corticosteroids and a control group without corticosteroids using the epidural injection technique.

The epineural peridural two-needle technique was developed for the common affected L5/S1 area. The required small volumes and reduced active ingredient amounts of the epineural peridural technique in the established perspectives for new active ingredients are applicable only in small amounts. The anti-interleukin 1 could be a model for such a new substance. It is available only in $2 \mathrm{ml}$ doses until today.

\section{Conclusion}

The topographic conditions of the anatomy in the anterolateral epidural space L5/S1 are convenient. An experienced and trained physician can reach this area without the help of image-guided techniques using the two-needle with the epidural-perineural injection technique. The common lumbar spine irritations of the roots L5 and S1 can be treated using small volumes and small means of antiphlogistic substances (one drop only).

The cranial nerve roots (L4 and higher) are not adapted to a dorsal interlaminar approach of the anterolateral epidural space because of a defined transdural passage of the needle. These unfrequent nerve root compression syndromes are treated with transforaminal techniques.

We recommend the improvement of the learning curve of the technical procedures in cadaver workshops using image intensifier. The described technique using the 29-gauge needle is not painful for the patient, needs no radiological support and requires only small drug amounts to anaesthetise the nerve root and perform an antiphlogistic effect.

\section{Conflict of interest statement None.}

Open Access This article is distributed under the terms of the Creative Commons Attribution Noncommercial License which permits any noncommercial use, distribution, and reproduction in any medium, provided the original author(s) and source are credited.

\section{References}

1. Becker C, Heidersdorf S, Drewlo S, Zirke de Rodriguez S, Kraemer J, Willburger R (2007) Efficacy of Epidural perineural Injections with autologous conditioned serum for lumbar radicular compression. An investigator-initiated, prospective, doubleblind, reference-controlled study. Spine 32:1803-1808

2. Bush K, Hillier S (1991) A controlled study of caudal epidural injections. Spine 16(5):572-575

3. Cuckler JM, Bernini PA, Wiesel SW, Booth RE, Rothman RH, Pickens GT (1985) The use of epidural steroids in the treatment of lumbar radicular pain. J Bone Joint Surg Am 67:63-66

4. Krämer J, Ludwig J, Bickert U, Owczarek V, Traupe M (1997) Lumbar epidural perineural injection: a new technique. Eur Spine J 6:357-361

5. Matthews A et al (1987) Back pain and sciatica. Controlled trials of manipulation traction, sclerosant and epidural injections. Br J Rheum 26:416-423

6. Ng L, Chaudhary N, Sell P (2005) The efficacy of corticosteroids in periradicular infiltration for chronic radicular pain. Spine 30(8):857-862

7. Snoek W, Weber H, Jorgenson B (1977) Double blind evaluation of extradural methylprednisolone for herniated lumbar discs. Acta Orthop Scand 48:535-641

8. Teske W, Zirke S, Trippe C, Krämer J, Willburger RE, Schott C, Theodoridis T, Beer AM, Molsberger A (2009) Die epidurale Injektionsbehandlung mit Lokalanästhetikum versus Kortison 
beim chronischen lumbalen Nervenwurzelkompressionssyndrom: eine prospektive Studie. Z Orthop Unfall 147(2):199-204

9. Theodoridis T, Krämer J (2009) spinal injection techniques. Thieme Verlag, Stuttgart
10. Yates D (1978) A comparison of the types of epidural injection commonly used in the treatment of low back pain and sciatica. Rheumatol Rehab 17:181-186 